\title{
Supervisor's Feedback on Progress of E-Logbook System of CPSP: A Cross-sectional Survey
}

\author{
Khalid Masood Gondal1, Junaid Sarfraz Khan² and Arslan Ahmed 3 \\ ${ }^{1}$ King Edward Medical University (KEMU), Lahore, Pakistan \\ ${ }^{2}$ National University of Medical Sciences (NUMS), Rawalpindi, Pakistan \\ ${ }^{3}$ Research Unit, College of Physicians and Surgeons Pakistan (CPSP), Lahore, Pakistan
}

\begin{abstract}
Objective: To determine the feedback of supervisors regarding role of e-logbook in monitoring of training, strengthening supervisor-supervisee relationship and improving overall environment of postgraduate training at College of Physicians and Surgeons Pakistan (CPSP).

Study Design: Cross-sectional survey.

Place and Duration of Study: College of Physicians and Surgeons Pakistan (CPSP) from July to December, 2017.

Methodology: All registered supervisors of CPSP who were monitoring training and had minimum three years postfellowship experience were included. Non-probability consecutive sampling technique was employed. HTML-based questionnaires were sent through e-log. Likert scale was used to rate statements about e-logbook, where "1" was "strongly disagree" and "5" denoted "strongly agree". The data were entered in SPSS version 21 and analysed through its statistical package.

Results: A total of 816 supervisors responded to the questionnaires (response rate of $65 \%$ ). Out of these, $74.3 \%$ were males and $25.7 \%$ were females with mean age of $52.8 \pm 6.9$ years. Majority of the supervisors agreed $(62 \%)$ or strongly agreed $(10 \%)$ that e-logbook has helped to improve the supervisor-supervisee relationship. More than half $(60 \%)$ of the supervisors agreed, whereas some $(19.3 \%)$ strongly agreed that e-logbook is a better monitoring tool than conventional logbook. The supervisors believed that overall training environment has improved with the introduction of e-log system ( $51 \%$ agreed and $9 \%$ strongly agreed). The age of supervisors and duration of supervisorship had no statistically significant effect on the responses of supervisors to various statements about e-logbook.

Conclusion: Supervisors perceive electronic logbooks as a useful medium for training monitoring and improvement of the relationship between supervisors and their residents. They have shown wide acceptability to the e-log system. E-log should continue as the primary monitoring system of the training programmes of CPSP.
\end{abstract}

Key Words: Medical education, Medical residency, Educational technology.

How to cite this article: Gondal KM, Khan JS, Ahmed A. Supervisor's feedback on progress of e-logbook system of CPSP: A cross-sectional survey. J Coll Physicians Surg Pak 2020; 30(2):139-143.

\section{INTRODUCTION}

Introduction of technology has revolutionised the postgraduate medical education in the twenty-first century. ${ }^{1}$ Technology is proving useful in attaining desired professional growth through easy access to learning resources, and effective utilisation of this information for the development of knowledge and skills.2,3 Electronic databases such as electronic portfolios (e-portfolio) or electronic logbooks, are now rapidly replacing the traditional paper-based logbooks. 4 College of Physicians and Surgeons Pakistan (CPSP) is the prime postgraduate medical institute of Pakistan. Traditionally, CPSP has used paper based logbooks which, although quite useful for training monitoring, had certain

Correspondence to: Prof. Khalid Masood Gondal, King Edward Medical University (KEMU), Lahore, Pakistan

E-mail: khalidmasoodgondal@yahoo.com

Received: January 04, 2020; Revised: January 15, 2020;

Accepted: January 17, 2020 limitations. 5,6 To counter these deficiencies, CPSP introduced the electronic version of logbook, the e-logbook, in 2011.7 The e-logbook of CPSP is in its $9^{\text {th }}$ year of induction. Earlier studies have shown e-logbook to be a valuable tool for training monitoring. 6,8

The success of an electronic logbook system depends on its ability to focus on students' satisfaction, flexible nature, ease of access to the learning material, costeffectiveness and strengthening of supervisorsupervisee relationship. ${ }^{9,10}$ The question is, after nine years of induction, does the e-log system of CPSP fulfill these fundamental requirements? E-log system has undergone various modifications from time to time to make it a more useful tool. The impact of these changes still remains to be ascertained.

This study was, therefore, designed with the aim to determine the feedback of supervisors regarding role of e-logbook in monitoring of training, strengthening supervisor-supervisee relationship, and improving 
overall environment of postgraduate training at CPSP. The results from this study may improve the monitoring, and evaluation of postgraduate training at CPSP.

\section{METHODOLOGY}

A cross-sectional survey was conducted during six month period from 1st of July to 31st of December, 2017. All the registered supervisors of CPSP with minimum three years post-fellowship experience were included in the study. Supervisors, who were currently not supervising any trainee and those who had withheld their supervisory status due to any reason for a period of more than 3 months, were excluded from the study. Non-probability consecutive sampling technique was employed and HTML-based questionnaires were sent to all the registered supervisors fulfilling the inclusion criteria. The questionnaires were sent through e-logbook and implied consents were assumed for those participants returning the filled questionnaires.

Ethical approval was taken from the Advanced Studies and Research Board (AS\&RB) of University of Health Sciences, Lahore; and the Ethical Review Board of the CPSP. The participants were informed through e-logbook before opening the questionnaire that the participation was merely on voluntary basis and would have no impact on the supervisory status. Factitious numbers were used throughout the study. A reminder was served via email to all the supervisors and trainees, who did not respond to the questionnaire within one month from the time of sending questionnaire.

The web-based questionnaire was designed based upon AMEE Guide 87 for questionnaire development. ${ }^{11}$ As per these guidelines, a comprehensive review of available literature was conducted followed by Focus Group Discussions (FGDs) with supervisors and synthesis of literature review and data from FGDs. The questionnaire comprised of nine items (Table I), which were closeended statements concerning the usefulness of e-log in residency training. Likert scale was used to rate the statements. The scale ranged from 1-5, where "1" was "strongly disagree" and "5" meant "strongly agree". The questionnaire was pilot studied before sending to study participants.

The data were entered in SPSS version 21 and analysed through its statistical package. Descriptive statistics were applied and frequencies and percentages were used for qualitative data, and mean $\pm S D$ for quantitative data. The reliability of the questionnaire was assessed through SPSS reliability item statistics, which showed a high Cronbach's alpha value (0.809) i.e., a high internal reliability of the questionnaire used. Normality of data was assessed through Shapiro-Wilk Test, which showed that data were not normally distributed $(p<0.05)$, therefore, non-parametric test i.e., Kruskal-Wallis test ${ }^{12}$ was applied to compare the data after stratification for age of supervisors and duration of supervisorship. A p-value of $<0.05$ was taken as statistically significant.

\section{RESULTS}

Questionnaires were sent to 1,258 supervisors that fulfilled the selection criteria. A total of 816 supervisors responded (response rate of $65 \%$ ) and were included in the study. Out of these, 606 (74.3\%) were males and 210 $(25.7 \%)$ were females. The minimum age of supervisors was 35 years and maximum age was 80 years with mean age of $52.8 \pm 6.9$ years. The mean duration of supervisorship was $3.8 \pm 4.2$ years. The demographic characteristics of the supervisors are given in Table II.

The supervisors were asked whether e-log has helped to improve the supervisor-supervisee relationship. Majority of the supervisors (62\%) agreed that e-logbook has helped to improve the supervisor-supervisee relationship, while $10 \%$ strongly agreed to this statement. The second statement was that whether supervisors provide regular feedback to their residents through e-logbook. The results showed that more than half of the supervisors $(62 \%)$ agree that they provide regular feedback to their residents through e-logbook; and some of the supervisors $(16 \%)$ strongly agreed to this statement.

Majority $(60 \%)$ of the supervisors agreed to the statement that e-logbook is a better monitoring tool than

Table I: Statements about utility of e-log asked from supervisors in the HTML questionnaire.

\begin{tabular}{l}
\hline 1. E-log has helped to improve - supervisor-supervisee relationship. \\
\hline 2. I provide regular feedback to my residents. \\
3. My residents perform regular entries. \\
\hline 4. E-log is a better monitoring tool than conventional logbook. \\
\hline 5. Entry of cases by residents should be time-bound. \\
6. E-log is easy to use and interface is user-friendly. \\
7. Entering data on e-log is not a time-taking process. \\
8. Overall training environment has improved after introduction of e-logbook. \\
\hline 9. E-log needs further improvement to make it a better monitoring tool.
\end{tabular}

Table II: Demographic characteristics of the supervisors included in the study $(\mathrm{N}=816)$.

\begin{tabular}{l|c|c}
\hline Variable & $\begin{array}{c}\text { No. of supervisors } \\
(\mathrm{n})\end{array}$ & $\begin{array}{c}\text { Percentage } \\
(\%)\end{array}$ \\
\hline Gender & 606 & 74.30 \\
Males & 210 & 25.70 \\
Females & 816 & 100 \\
Total & & \\
\hline Age group & 287 & 35.2 \\
35-50 years & 506 & 62.0 \\
$51-65$ years & 23 & 2.8 \\
$66-80$ years & 816 & 100 \\
Total & & \\
\hline Duration of supervisorship & 629 & 77.1 \\
$<6$ years & 113 & 13.8 \\
$6-10$ years & 74 & 9.10 \\
$>10$ years & 816 & 100 \\
Total & & \\
\hline
\end{tabular}


Table III: Responses of supervisors to various statements about e-logbook

\begin{tabular}{|c|c|c|c|c|c|c|c|}
\hline \multirow[t]{2}{*}{ Sr. No. } & \multirow[t]{2}{*}{ Statements } & \multirow{2}{*}{$\begin{array}{l}\text { Mean } \\
\text { score }\end{array}$} & \multirow[b]{2}{*}{$\begin{array}{l}\text { Strongly } \\
\text { disagree } \\
\text { (1) }\end{array}$} & \multicolumn{4}{|c|}{ Response on Likert scale } \\
\hline & & & & $\begin{array}{c}\text { Disagree } \\
(2)\end{array}$ & $\begin{array}{c}\text { Neutral } \\
\text { (3) }\end{array}$ & $\begin{array}{c}\text { Agree } \\
(4)\end{array}$ & $\begin{array}{c}\text { Strongly } \\
\text { agree } \\
(5)\end{array}$ \\
\hline 1. & E-log has helped to improve supervisor-supervisee relationship. & 3.68 & $28(3.4 \%)$ & $68(8.3 \%)$ & $127(15.6 \%)$ & $507(62.1 \%)$ & $86(10.5 \%)$ \\
\hline 2. & I provide regular feedback to my residents. & 3.84 & $16(2.0 \%)$ & $54(6.6 \%)$ & $108(13.2 \%)$ & $505(61.9 \%)$ & $133(16.3 \%)$ \\
\hline 3. & My residents perform regular entries. & 3.50 & $29(3.6 \%)$ & $131(16.1 \%)$ & $135(16.5 \%)$ & $446(54.7 \%)$ & $75(9.2 \%)$ \\
\hline 4. & E-log is a better monitoring tool than conventional logbook. & 3.87 & $19(2.3 \%)$ & $60(7.4 \%)$ & $91(11.2 \%)$ & $488(59.8 \%)$ & $158(19.4 \%)$ \\
\hline 5. & Entry of cases by residents should be time-bound. & 3.76 & $17(2.1 \%)$ & $85(10.4 \%)$ & $112(13.7 \%)$ & $465(57.0 \%)$ & $137(16.8 \%)$ \\
\hline 6. & E-log is easy to use and interface is user-friendly. & 3.78 & $13(1.6 \%)$ & $85(10.4 \%)$ & $82(10.0 \%)$ & $525(64.3 \%)$ & $111(13.6 \%)$ \\
\hline 7. & Entering data on E-log is not a time-taking process. & 3.78 & $13(1.6 \%)$ & $85(10.4 \%)$ & $82(10.0 \%)$ & $525(64.3 \%)$ & $111(13.6 \%)$ \\
\hline 8. & $\begin{array}{l}\text { Overall training environment has improved after introduction } \\
\text { of e-logbook. }\end{array}$ & 3.54 & $15(1.8 \%)$ & $95(11.6 \%)$ & $215(26.3 \%)$ & $414(50.7 \%)$ & $77(9.4 \%)$ \\
\hline 9. & $\begin{array}{l}\text { E-log needs further improvement to make it a better } \\
\text { monitoring tool. }\end{array}$ & 3.91 & $13(1.6 \%)$ & $22(2.7 \%)$ & $113(13.8 \%)$ & $542(66.4 \%)$ & $126(15.4 \%)$ \\
\hline
\end{tabular}

conventional logbook; whereas, $19.3 \%$ strongly agreed. Most of the supervisors found that overall training environment has improved with the introduction of e-log system as $51 \%$ supervisors agreed and $9 \%$ strongly agreed with the statement.

More than half $(56.9 \%)$ of the supervisors agreed that entries by trainees and feedback from supervisors should be time-bound in order to achieve better outcome; while, some $(16.7 \%)$ strongly agreed to this statement. More than half of the supervisors (64\%) agreed that they found e-logbook easier to use and its interface is userfriendly; and $14 \%$ of supervisors strongly agreed in this regard. Almost $50 \%$ of the supervisors believed that data entering on e-log system is not a time-taking process as $372(46 \%)$ and $73(9 \%)$ out of 816 supervisors agreed and strongly agreed, respectively. Whether e-logbook needs further improvement or not, suggestions from supervisors were sought. Majority were in favour (66.4\% agreed and $15.4 \%$ strongly agreed) that it needs further improvement to make it more effective monitoring tool; and very few of them disagreed in this regard. The mean scores and the results on Likert scale obtained from the responses of supervisors to various statements to elogbook are given in Table III.

The responses of supervisors were stratified with respect to the age groups of supervisors and duration of supervisorship to observe their effect on the results. As the data did not follow normal distribution (Shapiro-Wilk Test showed that data were not normally distributed i.e., $\mathrm{p}<0.05$ ), therefore, non-parametric test i.e., KruskalWallis test was applied to compare the data after stratification for age of supervisors and duration of supervisorship. A non-significant $p$-value $(>0.05)$ showed that the age of supervisors and duration of supervisorship had no statistically significant effect on the responses of supervisors to various statements about e-logbook.

\section{DISCUSSION}

The present study is a continuation of a series of previous studies conducted by the same authors on the utilisation of e-logbook. 6,8 Both studies included cohorts that differed in respect to study populations and the time-frame selected i.e., $2014^{8}$ and $2015^{6}$. The current study was conducted in 2017. The previous studies supported the utility of e-log as a good monitoring tool similar to the results of this study.

The results from the current study show that majority of the supervisors believed that e-logbook is a better monitoring tool than the conventional logbook. Systematic data review of published literature on the effectiveness of electronic logbooks show that introduction of technology in the medical education system may result in better management of workflow of trainees, profiling of their experience and enhance decision-making skills. ${ }^{13}$ Results from the study show that majority of the supervisors agreed that e-logbook is a useful tool for training monitoring.

In a previous study conducted on RCSEd residents, it was concluded that the centralised electronic logbook system is a valuable tool for training monitoring. ${ }^{14}$ Studies on usefulness of electronic databases for postgraduate medical education found them to be a useful tool in monitoring the progress of trainees. ${ }^{15} \mathrm{~A}$ thorough search of literature revealed some contradictory evidence as well. Another study showed that only $30 \%$ of supervisors considered the use of electronic feedback systems in medical education to confer any benefit to the monitoring of training of residents. ${ }^{16}$

Literature is evident that the electronic logbooks are superior to their paper counterparts. In a previous study, two logbooks of surgeons 20 years apart were compared; and it was concluded that the electronic version allows trainees to make detailed entries and receive prompt supervision. ${ }^{17}$ Additionally, it is observed that the electronic databases, such as e-logbooks, are cost-effective and feasible tool for performance-tracking of medical students and allow medical professionals to maintain an online evidence of their experience, competencies and achievements, which serve as a valuable tool for the professional development. 18,19 
The results from the current study show that majority of the supervisors believed that e-logbook helps to improve the supervisor-supervisee relationship. A previous study conducted on pediatric residents in UK concluded that a strong supervisor-supervisee relationship is essential to encourage reflective practices among residents. ${ }^{20}$ Results from this study show that majority of the supervisors provide regular feedback to their residents. In a previous study on the Healthcare Supervision Logbook (HSL) of Sheffield Teaching Hospitals, a remarkable improvement was observed only after six months when $82 \%$ of the supervisors were providing daily feedback to their residents in contrast to only $2 \%$ earlier. 21 The role of electronic logbooks in improving feedback is thus obvious. The use of technology, however, may not be easily adaptable for some with limited exposure to electronic technology in the past and those without easy access to such facilities. ${ }^{22}$

Reliability of electronic logbooks may be an issue. In one of the studies, it was observed that electronic logbooks may not be a reliable tool for assessment due to fake entries by students and it was recommended that the supervisors must not rely solely on electronic logbooks for assessment.18 As per a cross-sectional study conducted in eight medical colleges of Bangladesh, it was found that majority of the students and supervisors believed that logbooks are only used as an assessment technique and have little application as a platform for providing feedback. ${ }^{23}$ In sharp contradiction, another Bangladeshi study showed that more than $80 \%$ of the supervisors were of the view that an electronic logbook system is the need of the hour, which should be in place for proper assessment of clinical skills of residents. ${ }^{24}$

The current study explored the effect of age of supervisors and duration of supervisorship on the responses of supervisors; and no statistical significant differences were observed in various groups. Thus, it may be concluded that e-log has similar level of utility for supervisors of different age groups and experience.

The authors acknowledge that although complete anonymity was exercised; but still the concerns of being assessed may give rise to some bias, while reporting actual feedback practices and data entry routines on e-logbook. Some of the supervisors were registered after the introduction of e-logbook and had little practical experience with the conventional logbook. Therefore, the comparison between the conventional and electronic versions of logbook may not be based on actual experience of these participants.

The authors recommend that further studies including indepth interviews can be carried out to further explore the perceptions of all the stakeholders including supervisors and trainees, about e-logbook of CPSP.

\section{CONCLUSION}

Based on the results of the current study and a thorough review of available literature, it may be concluded that the supervisors perceive electronic logbooks as a useful medium for training monitoring and improvement of the relationship between supervisors and their residents. The supervisors have shown wide acceptability to the e-log system. E-log is constantly evolving and the results from this study can drive this process in the right direction. Based on the results of this study, it can be concluded that e-log system should continue as the primary monitoring system of the training programmes of CPSP. Other developing countries of the region and the world can introduce electronic-based logbooks similar to e-log of CPSP, in order to improve the monitoring and evaluation of postgraduate medical education.

\section{ETHICAL APPROVAL:}

Ethical approval was taken from the Advanced Studies and Research Board (AS\&RB) of University of Health Sciences, Lahore and the Ethical Review Board of the CPSP.

\section{CONFLICT OF INTEREST:}

One of the authors is involved in the implementation of e-log since induction of e-logbook in CPSP. The authors were also involved in the previous studies conducted on e-logbook. 6,8 Both studies included cohorts that differed in respect to study populations and the time-frame selected.

\section{DISCLOSURE:}

The article is based on the PhD thesis of one of the authors.

\section{AUTHORS' CONTRIBUTION:}

KMG: The main author who conducted the study and has been involved in the implementation of e-log since 2011 and presented its study at various national and international forums, including Canada, Australia and Saudi Arabia.

JSK: Supervised this study and provided technical guidance throughout the study.

AA: Contributed with data collection and analysis.

\section{REFERENCES}

1. Miles CA, Lee AC, Foggett KA, Nair BK. Reinventing medical teaching and learning for the 21st century: Blended and flipped strategies. Arch Med Health Sci 2017; 5:97-102.

2. Maza EMT, Lozano MTG, Alarcón ACC, Zuluaga LM, Fadul MG. Blended learning supported by digital technology and competency-based medical education: A case study of the social medicine course at the Universidad de los Andes, Colombia. Intl J Educ Technol High Educ 2016; 13:27.

3. McCoy L, Pettit RK, Lewis JH, Bennett T, Carrasco N, Brysacz S, et al. Developing technology-enhanced active learning for medical education: challenges, solutions, and future directions. J Am Osteopat Assoc 2014; 115:202-11.

4. Belcher R, Jones A, Smith LJ, Vincent T, Naidu SB, Montgomery $\mathrm{J}$, et al. Qualitative study of the impact of an authentic electronic portfolio in undergraduate medical education. BMC Med Educ 2014; 14:265. 
5. College of Physicians and Surgeons Pakistan (CPSP), 2019. About College of Physicians and Surgeons, Pakistan. Website: https://www.cpsp.edu.pk [Assessed on: 17/12/2019].

6. Gondal KM, Iqbal U, Ahmed A, Khan JS. Supervisors' perspective on electronic logbook system for postgraduate medical residents of CPSP. J Coll Physicians Surg Pak 2017; 27:540-3.

7. E-logbook, College of Physicians and Surgeons, Pakistan (CPSP), 2019. Website: https://www.elogbook.cpsp.edu.pk [Assessed on: 17/12/2019].

8. Iqbal U, Gondal KM, Qureshi AU, Khan UA. E-log in monitoring of residency program: Trainees' perspective. J Coll Physicians Surg Pak 2015; 25:501-4.

9. Aresti N, Ramachandran M. Developing an electronic teaching and training portfolio. Curr Rev Musculoskel Med 2014; 7:172-6.

10. Van Der Vleuten CP, Schuwirth LWT, Driessen EW, Govaerts MJB, Heeneman S. Twelve tips for programmatic assessment. Med Teach 2015; 37:641-6.

11. Artino Jr AR, La Rochelle JS, Dezee KJ, Gehlbach H. Developing questionnaires for educational research: AMEE Guide No. 87. Med Teach 2014; 36:463-74.

12. Hanusz Z, Tarasinska J. Normalization of the KolmogorovSmirnov and Shapiro-Wilk tests of normality. Biom Lett 2015; 52:85-93.

13. Keenan $\mathrm{CR}$, Nguyen $\mathrm{HH}$, Srinivasan M. Electronic medical records and their impact on resident and medical student education. Acad. Psychiatry 2006; 30:522-7.

14. Lonergan PE, Mulsow J, Tanner WA, Traynor O, Tierney S. Analyzing the operative experience of basic surgical trainees in Ireland using a web-based logbook. BMC Med Educ 2011; 11:70.
15. Allum W, Hornby S, Khera G, Fitzgerald E, Griffiths G. General surgery logbook survey. RCS The Bulletin 2013; 95:1-6.

16. Tailor A, Dubrey S, Das S. Opinions of the ePortfolio and workplace-based assessments: A survey of core medical trainees and their supervisors. Clin Med (Lond) 2014; 14:510-6.

17. Thomas RL, Karanjia N. Comparison of $\mathrm{SHO}$ surgical logbooks: A generation apart. RCS Bull 2009; 91:356-9.

18. Fatemeh K, Alavinia S. Students' perception about Logbooks: Advantages, limitations and recommendations: A qualitative study. J Pak Med Assoc 2012; 62:1184-6.

19. Wan J, Metcalfe NH. Review of e-portfolio requirements and methodology. J Hosp Adm 2015; 5:29.

20. Goodyear HM, Bindal T, Wall D. How useful are structured electronic portfolio templates to encourage reflective practice? Med Teach 2013; 35:71-3.

21. Gray TG, Hood G, Farrell T. Integration of healthcare supervision logbook smartphone app into clinical practice to record feedback on medical training. BMJ 2016; 2:48-51.

22. Aboshady OA, Radwan AE, Eltaweel AR, Azzam A, Aboelnaga AA, Hashem HA, et al. Perception and use of massive open online courses among medical students in a developing country: multicenter cross-sectional study. BMJ Open 2015; 5:e006804.

23. Noman F, Asaduzzaman AKM, Talukder HK, Arefin AS. Rahman S. Evaluation of internship assessment in medical colleges of Bangladesh. Bangladesh J Med Educ 2017; 814-7.

24. Sultana HS, Ara I, Talukder HK, Asaduzzaman AKM, Nargis T. Supervisors' opinion regarding the situation of postgraduate fellowship training in gynaecology and obstetrics of selected medical colleges in Bangladesh. Bangladesh $J$ Med Educ 2017; 6:8-11. 